\title{
Influence of Inter- and Intramolecular Hydrogen Bonding on Kemp Decarboxylations from QM/MM Simulations
}

\author{
Orlando Acevedo and William L. Jorgensen* \\ Department of Chemistry, Yale University, 225 Prospect Street, \\ New Haven, Connecticut 06520-8107.
}

Supporting Material

Figure S1. For 1 - Solute-solvent energy pair distribution in methanol.........................S2

Figure S2. For 1 - Solute-solvent energy pair distribution in chloroform....................S2

Figure S3. For 1 - Solute-solvent energy pair distribution in THF........................... 3

Figure S4. For 3 - Solute-solvent energy pair distribution in water............................S3

Figure S5. For 2 - Solute-solvent energy pair distribution in water........................ 4

Figure S6. For 2 - Solute-solvent energy pair distribution in acetonitrile....................S4

Figure S7. For 2 - Solute-solvent energy pair distribution in DMSO.....................S5

Gaussian 03 reference........................................................... 5 


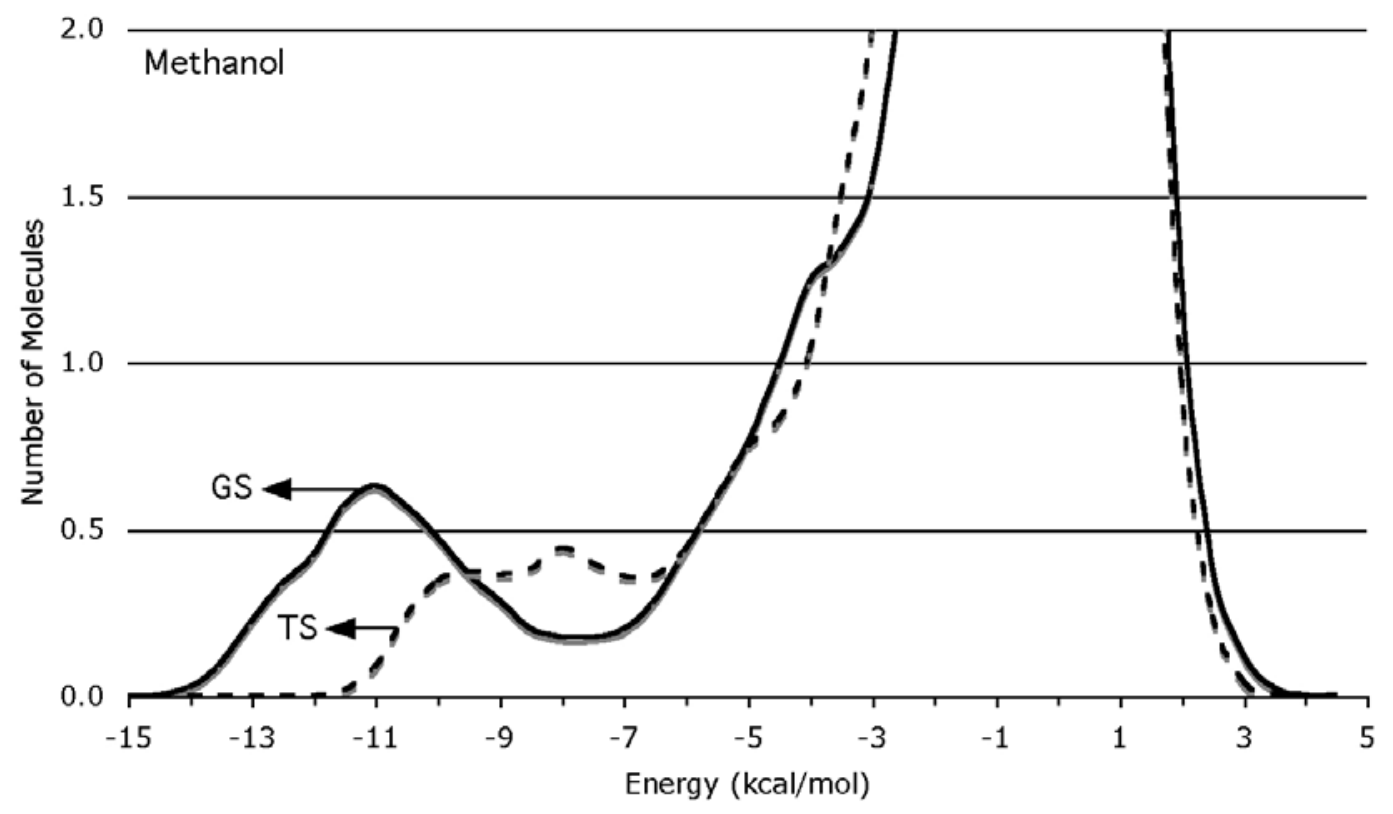

Figure S1. Solute-solvent energy pair distributions for the Kemp decarboxylation of $\mathbf{1}\left(\mathrm{R}_{1}=\mathrm{H}\right.$, $\mathrm{R}_{2}=\mathrm{H}$ ) in methanol for the reactant (GS) and transition structure (TS). The ordinate records the number of solvent molecules that interact with the solutes with their interaction energy on the abscissa. Units for the ordinate are number of molecules per kcal $/ \mathrm{mol}$.

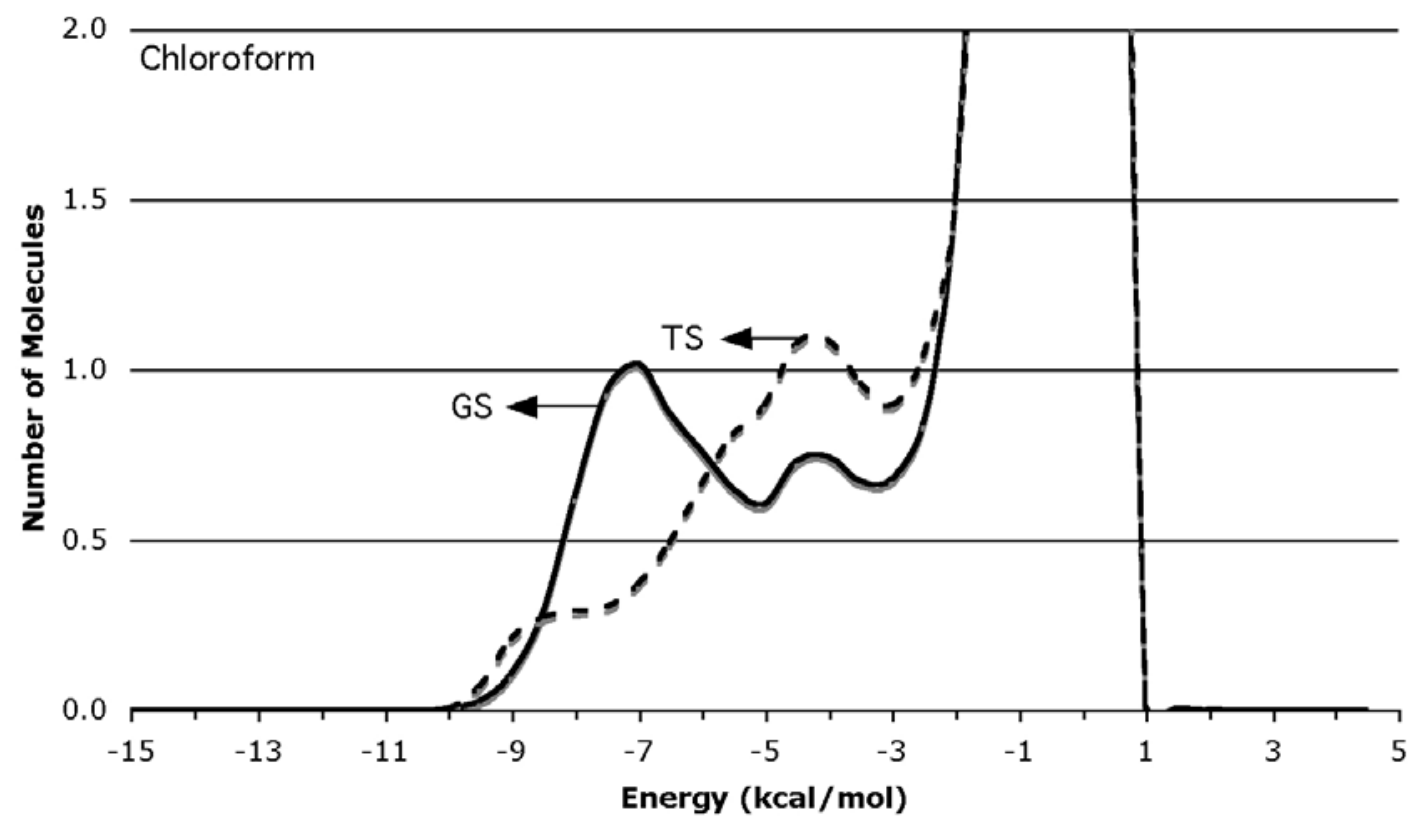

Figure S2. Solute-solvent energy pair distributions for the Kemp decarboxylation of $\mathbf{1}\left(\mathrm{R}_{1}=\mathrm{H}\right.$, $\mathrm{R}_{2}=\mathrm{H}$ ) in chloroform for the reactant (GS) and transition structure (TS). The ordinate records the number of solvent molecules that interact with the solutes with their interaction energy on the abscissa. Units for the ordinate are number of molecules per $\mathrm{kcal} / \mathrm{mol}$. 


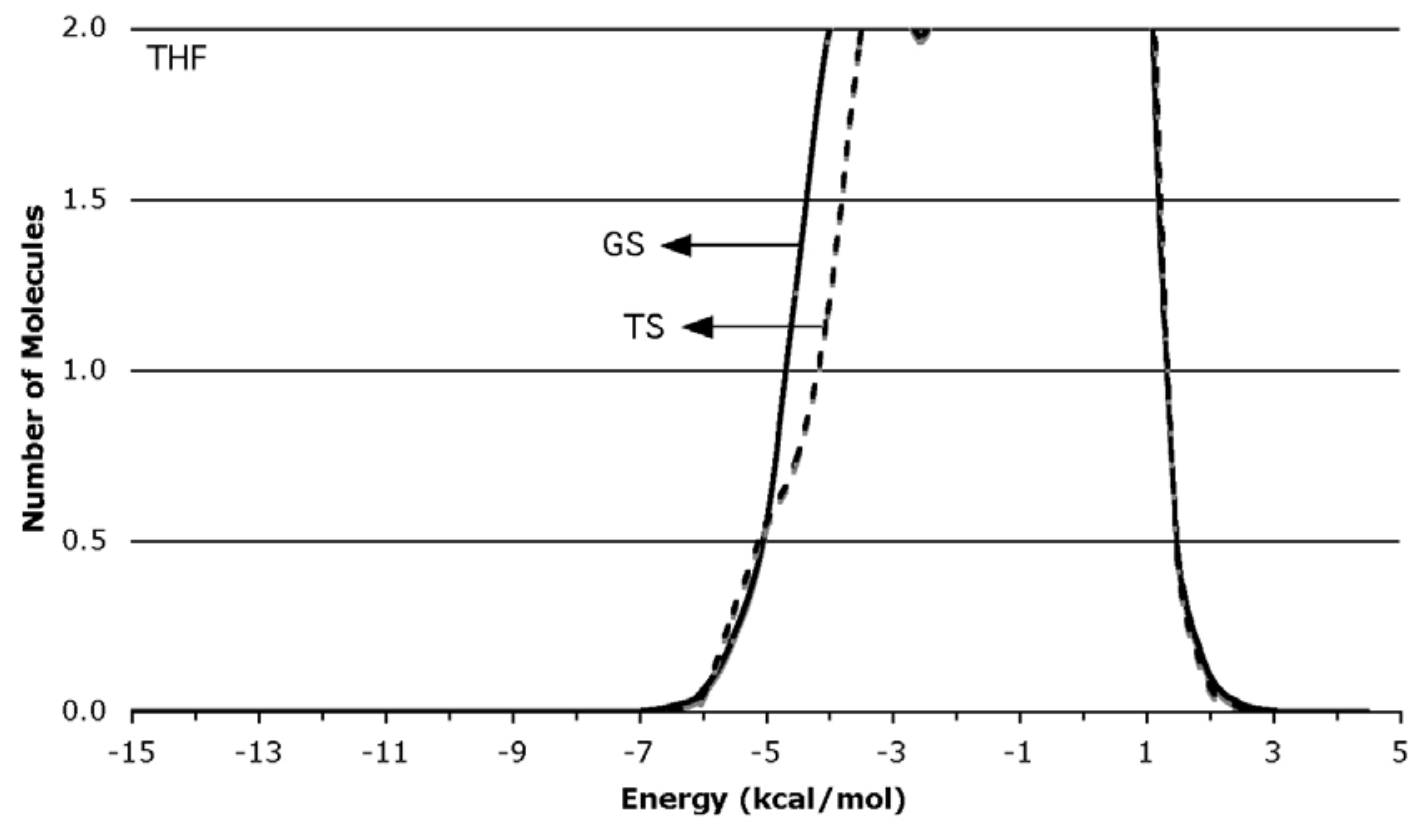

Figure S3. Solute-solvent energy pair distributions for the Kemp decarboxylation of $\mathbf{1}\left(\mathrm{R}_{1}=\mathrm{H}\right.$, $\mathrm{R}_{2}=\mathrm{H}$ ) in THF for the reactant (GS) and transition structure (TS). The ordinate records the number of solvent molecules that interact with the solutes with their interaction energy on the abscissa. Units for the ordinate are number of molecules per $\mathrm{kcal} / \mathrm{mol}$.

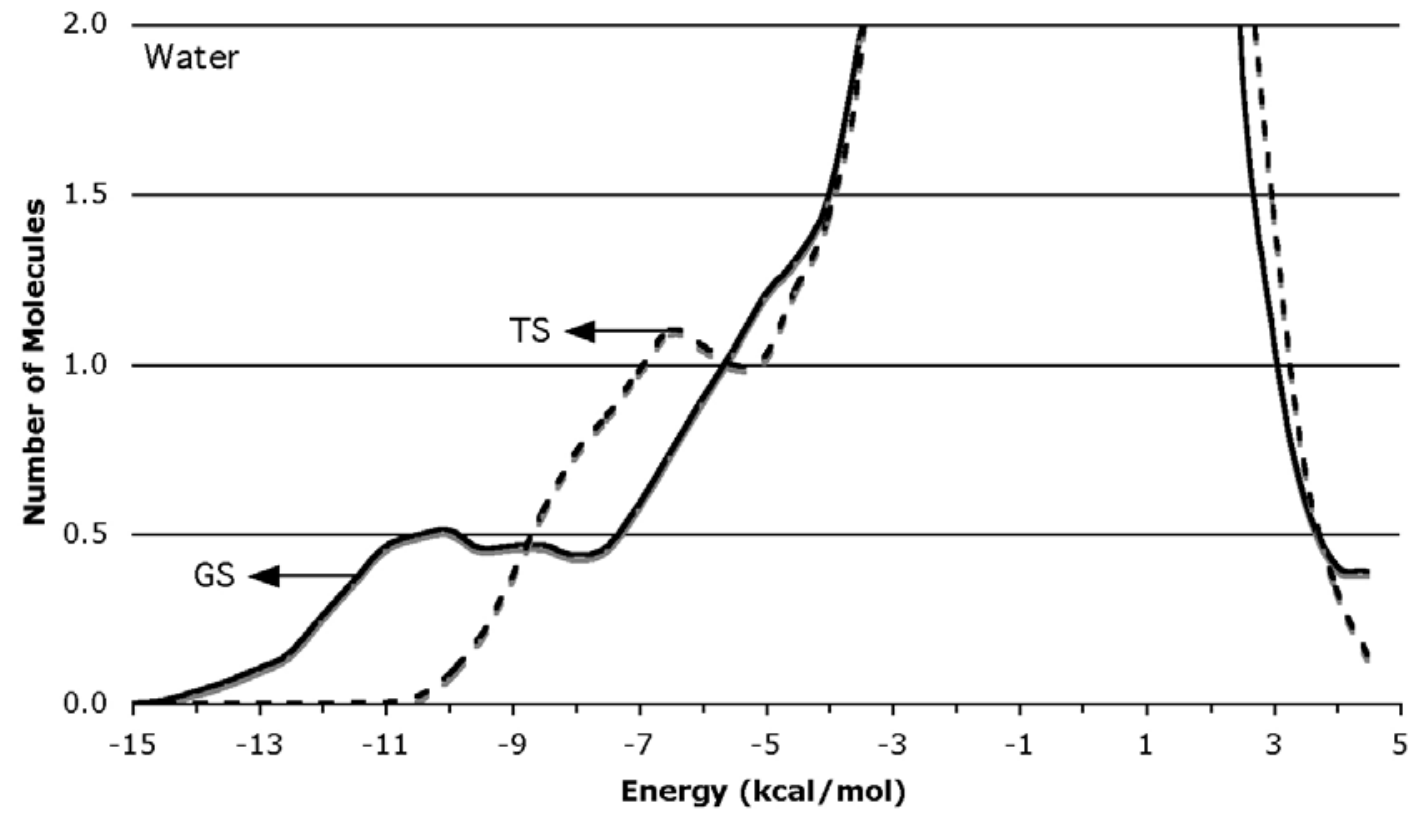

Figure S4. Solute-solvent energy pair distributions for the Kemp decarboxylation of $\mathbf{3}\left(\mathrm{R}_{1}=\mathrm{H}\right.$, $\mathrm{R}_{2}=\mathrm{OH}$ ) in water for the reactant (GS) and transition structure (TS). The ordinate records the number of solvent molecules that interact with the solutes with their interaction energy on the abscissa. Units for the ordinate are number of molecules per $\mathrm{kcal} / \mathrm{mol}$ 


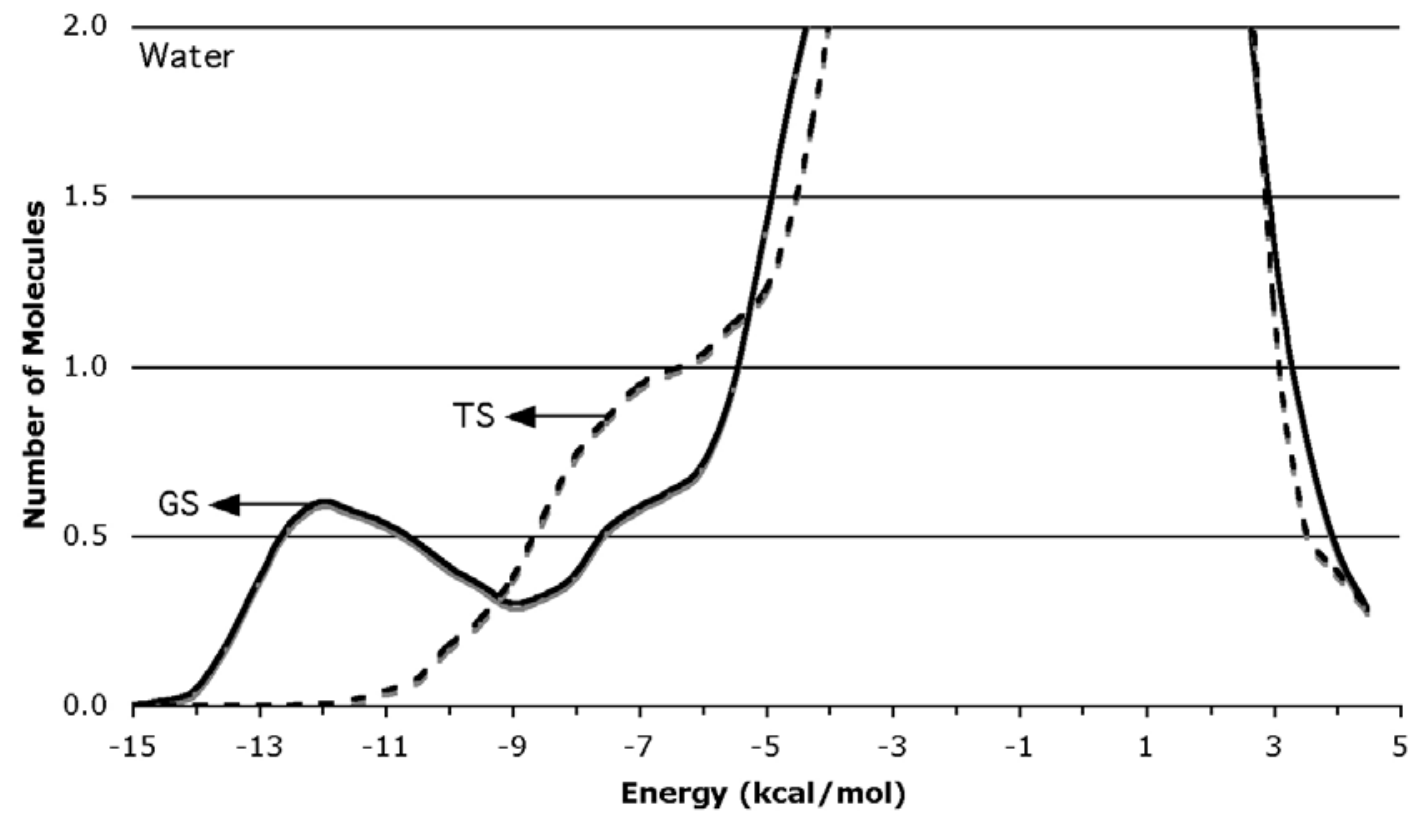

Figure S5. Solute-solvent energy pair distributions for the Kemp decarboxylation of $\mathbf{2}\left(\mathrm{R}_{1}=\mathrm{OH}\right.$, $\mathrm{R}_{2}=\mathrm{H}$ ) in water for the reactant (GS) and transition structure (TS). The ordinate records the number of solvent molecules that interact with the solutes with their interaction energy on the abscissa. Units for the ordinate are number of molecules per $\mathrm{kcal} / \mathrm{mol}$.

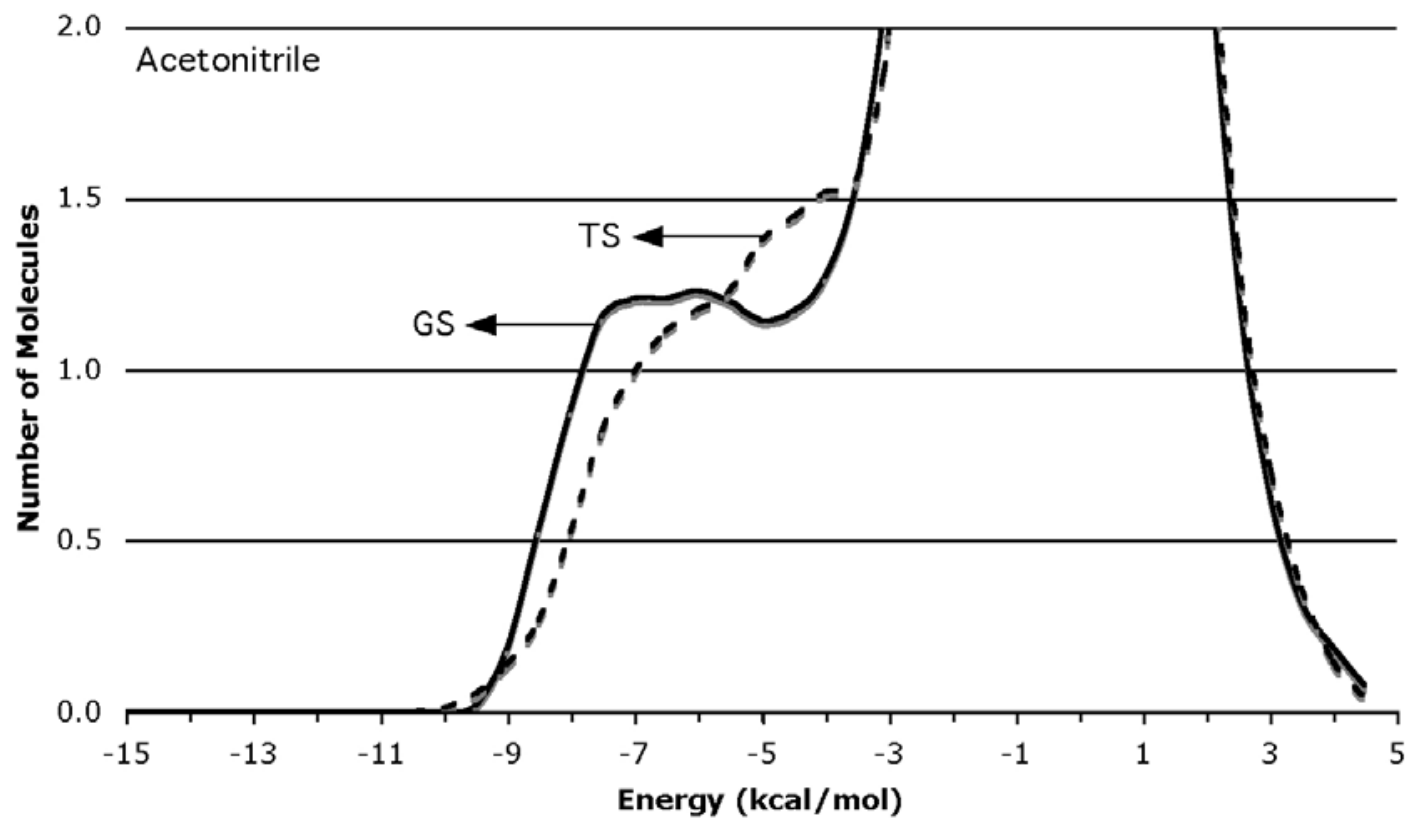

Figure S6. Solute-solvent energy pair distributions for the Kemp decarboxylation of $\mathbf{2}\left(\mathrm{R}_{1}=\mathrm{OH}\right.$, $\mathrm{R}_{2}=\mathrm{H}$ ) in acetonitrile for the reactant (GS) and transition structure (TS). The ordinate records the number of solvent molecules that interact with the solutes with their interaction energy on the abscissa. Units for the ordinate are number of molecules per $\mathrm{kcal} / \mathrm{mol}$. 


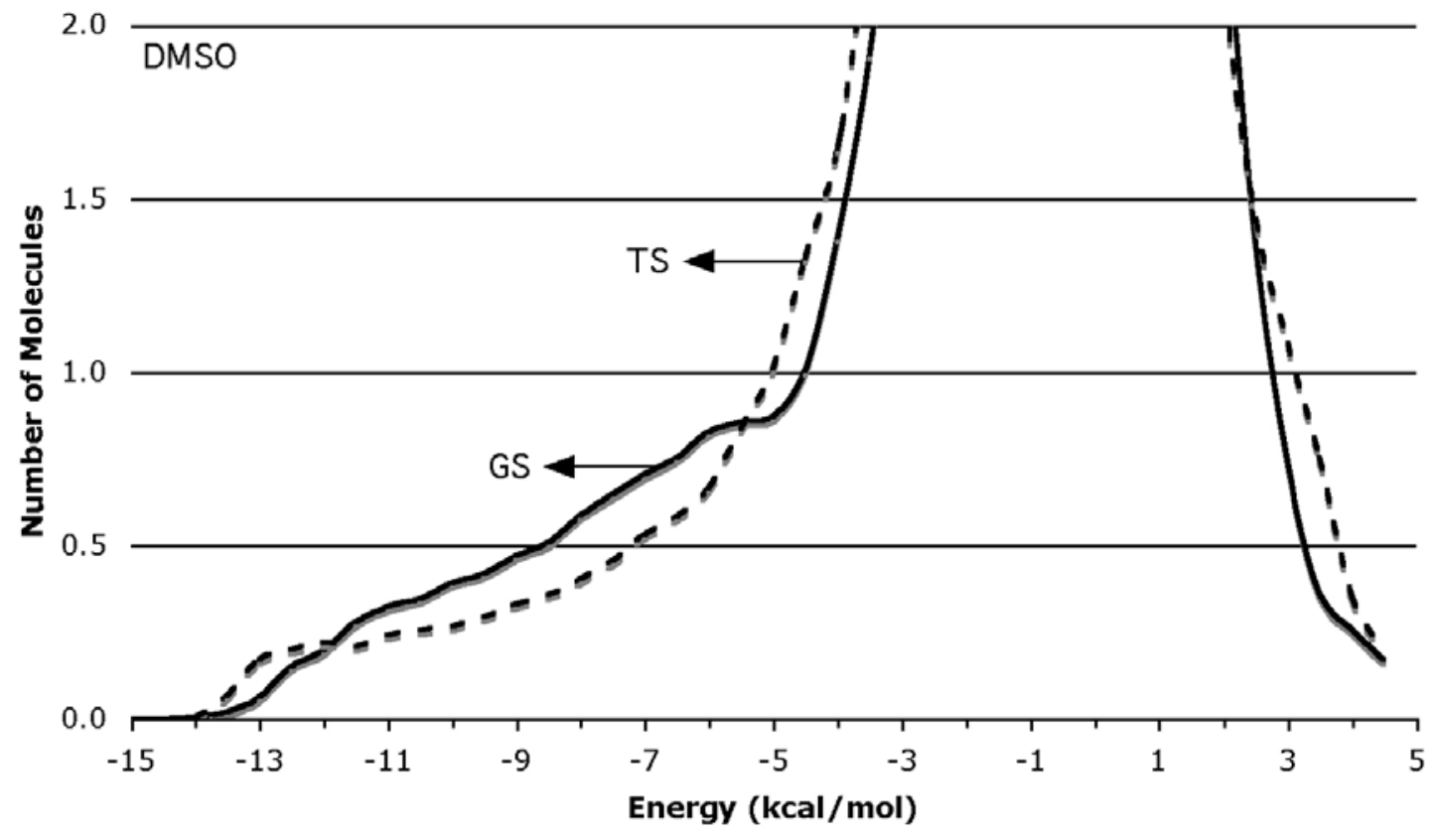

Figure S7. Solute-solvent energy pair distributions for the Kemp decarboxylation of $\mathbf{2}\left(\mathrm{R}_{1}=\mathrm{OH}\right.$, $\mathrm{R}_{2}=\mathrm{H}$ ) in DMSO for the reactant (GS) and transition structure (TS). The ordinate records the number of solvent molecules that interact with the solutes with their interaction energy on the abscissa. Units for the ordinate are number of molecules per $\mathrm{kcal} / \mathrm{mol}$.

\section{Gaussian 03 Reference}

Gaussian 03 , Revision B.03,

M. J. Frisch, G. W. Trucks, H. B. Schlegel, G. E. Scuseria,

M. A. Robb, J. R. Cheeseman, J. A. Montgomery, Jr., T. Vreven,

K. N. Kudin, J. C. Burant, J. M. Millam, S. S. Iyengar, J. Tomasi,

V. Barone, B. Mennucci, M. Cossi, G. Scalmani, N. Rega,

G. A. Petersson, H. Nakatsuji, M. Hada, M. Ehara, K. Toyota,

R. Fukuda, J. Hasegawa, M. Ishida, T. Nakajima, Y. Honda, O. Kitao,

H. Nakai, M. Klene, X. Li, J. E. Knox, H. P. Hratchian, J. B. Cross,

C. Adamo, J. Jaramillo, R. Gomperts, R. E. Stratmann, 0. Yazyev,

A. J. Austin, R. Cammi, C. Pomelli, J. W. Ochterski, P. Y. Ayala,

K. Morokuma, G. A. Voth, P. Salvador, J. J. Dannenberg,

V. G. Zakrzewski, S. Dapprich, A. D. Daniels, M. C. Strain,

0. Farkas, D. K. Malick, A. D. Rabuck, K. Raghavachari,

J. B. Foresman, J. V. Ortiz, Q. Cui, A. G. Baboul, S. Clifford,

J. Cioslowski, B. B. Stefanov, G. Liu, A. Liashenko, P. Piskorz,

I. Komaromi, R. L. Martin, D. J. Fox, T. Keith, M. A. Al-Laham,

C. Y. Peng, A. Nanayakkara, M. Challacombe, P. M. W. Gill,

B. Johnson, W. Chen, M. W. Wong, C. Gonzalez, and J. A. Pople, Gaussian, Inc., Pittsburgh PA, 2003. 